\title{
A Comparison of Near-Hidden and Information Asymmetry Interference Problems in Wireless Mesh Networks
}

\author{
Sadiq Shah*, Muhammad Atif ${ }^{\dagger}$, Samiullah Khan ${ }^{\ddagger}$, Misbah Daud ${ }^{\S}$ and Fahim Khan Khalil 9 \\ * Department of Computer Science, FATA University, FR Kohat, \\ $\dagger \ddagger \S$ Institute of Business Management Sciences, The University of Agriculture Peshawar-Pakistan
}

\begin{abstract}
Multi-radio Multi-channel (MRMC) Wireless Mesh Networks (WMNs) have made quick progress in current years to become the best option for end users due to its reliability and low cost. Although WMNs have already been used still the capacity of WMNs is limited due to information asymmetry and near hidden interference among frequency channels. In the past, various research studies have been done to investigate both these issues. To minimise both these interference types and maximise network capacity; channel assignment has always been a critical area of research in WMNs. In this research, a comparative analysis is done between NH and IA interference based on their impact on network capacity. This comparison is made using the existing Optimal Channel Assignment Model (OCAM). After extensive simulations, it is figured out that $\mathrm{NH}$ interference performs a major role in degrading overall network capacity up to $4 \%$ in comparison to IA interference. Further, in this research an optimal channel assignment model Information Asymmetry and Near Hidden Minimization (INM) model is proposed that collectively minimises both $\mathrm{NH}$ and IA interference problems. The proposed model considers three non-overlapping channels 1, 6 and 11 from IEEE802.11b standard. For simulations, four different Multi-radio Multi-channel Wireless mesh topologies have been considered to find out the average network capacity. An extensive simulation in OPNET shows that the proposed INM model performs $7 \%$ better than the existing OCAM model in maximising the WMN net capacity.
\end{abstract}

Keywords-Wireless Mesh Network (WMN); near hidden and information asymmetry interference; non-overlapping channels

\section{INTRODUCTION}

All types of Wireless networks develop into the next generation to offer improved and attractive services. Among those networks, Wireless Mesh Network (WMN) has emerged in recent times. Three different types of nodes are used in a wireless mesh network that is mesh router, mesh client and gateway router [1]. In WMN nodes are connected with one another, and these nodes operate as a router as well as host, sending data to the node which are not in transmission range with the help of intermediate nodes. Due to its different features, i.e. reliability, redundancy and low cost the WMNs are deployed most quickly. In WMN when one link is down or not working, communication can be done with the help of other links. Due to self-forming and self-configuration, a WMN convey several advantages to its users, i.e. low costs, network maintenance, reliable coverage and robustness [3].

For Commercial users, WMN offers a guarantee for their applications. Both conventional and mesh clients used the WMNs to connect to the backbone or mesh routers, and these routers are fixed, or minimum mobility and these nodes operate as a router as well as host. In WMN nodes send data to the destination directly or with the help of intermediate nodes [12]. A wireless mesh network made from multiple wireless nodes. In a wireless mesh network, every node can transmit information directly to single or multiple peer nodes. In a wireless mesh network, new links are created, and the nodes are connected to each other with the help of these links. When the numbers of interconnected nodes are increased at that time the possible path and the total bandwidth is also increased [5]. Dynamic channel assignment permits that different channel may be assigned to different interfaces and these interfaces may regularly change between multiple channels [18].

In WMN routers are usually fixed or minimal mobility, and there is no power issue unlike in sensor network. Usually, the structure design of WMN consists of three levels. First one is mesh gateways second one is mesh router, and the third one is mesh, client. In WMN the internet backbone is connected with mesh backbone with the help of mesh gateways [4]. In a wireless mesh network, the second level consists of mesh router/backbone. The mesh backbone consists of mesh routers, and these mesh routers are fixed sites. These mesh router collect data from mesh client and send to gateway router and from gateway to the internet. The third and last level of WMN is mesh client. The mesh clients are the actual transmission and reception of wireless mesh network [7].

In Fig. 1 the mesh backbone receives data which are sending by mesh client. The mesh backbone then forwards data to mesh gateway and then to the Internet. Internet is shown in the form of cloud. These mesh routers have no mobility or fixed, and multiple interfaces are assigned to them. In Fig. 1 the mesh client is laptops, computers and mobiles as shown. The links are wireless links the works as backbone among all the mesh routers. The mesh routers have multiple interfaces.

\section{A. Applications of WMN}

Wireless mesh networks consist of fixed or mobile devices. The solutions are as different as communication needs, for example in unmanageable environments such as emergency situations, oil rigs, tunnels, battlefield surveillance, high-speed mobile video applications on board public transport. An important possible application for wireless mesh networks is VoIP. By using a Quality of Service scheme, some current applications are mentioned below [8]. 


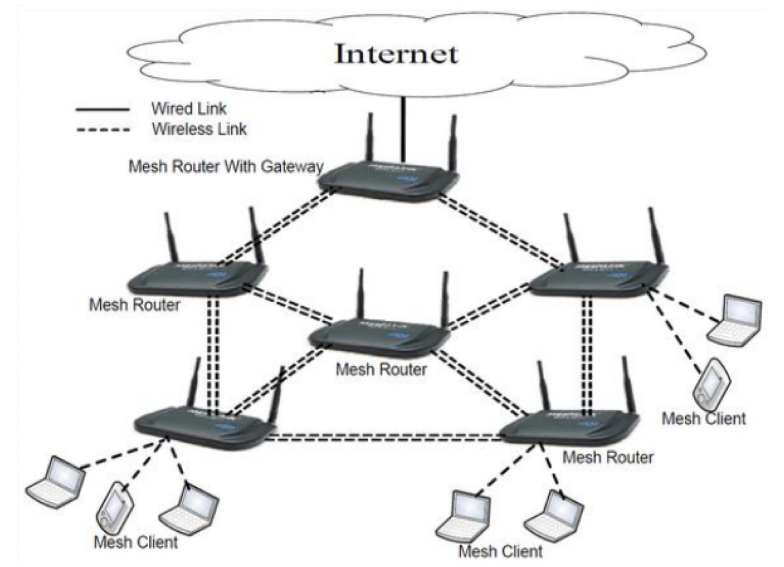

Fig. 1. Diagram of wireless mesh network.

- U.S. military forces connect their computers through wireless mesh networking field operations.

- Now in houses, electric meters are used that transmit their readings from one to another and lastly to the main office for billings without the requirement of human meter readers.

\section{B. Multi-Radio Multi-Channel Wireless Mesh Network}

"In MR-MCWMN have multiple interfaces and more than one frequency channels may be assigned to them. In this network particular wireless mesh routers work as a gateway and these gateways routers are connected to the internet or another network that may be heterogeneous. MRMC-WMNs have got development quickly in current years and have become the best option for end users as it is trusty, scalable and can expend network connectivity on the last mile. WMN provide excessive throughput because of its multi-radio and multichannel technology [10]. A WMN can be categorized into three sections. The first section includes gateways. Through these gateways routers, the wireless mesh network is connected to the internet as discussed in Fig. 1. The second section consists of mesh router. These mesh router forward information inside the WMNs on the interest of end users and these mesh router is also called nodes. The third section consists of mesh client or wireless LANs. In wireless mesh network end users are the real sender and receiver of data. These mesh routers send and receive data if these routers work on the same frequency channel. Due to multiple channel and multiple interfaces use interference is tack place that causes network throughput degradation [18]."

Single-radio single-channel (SR-SC) is a type of wireless mesh network (WMN). Which consist of mesh router and every mesh router consist of only one network interface card. Due to frequent backoff and packet collisions, the capacity and throughput of the network are suffering and low. In this research, multi-radio multi-channel $\mathrm{WMN}$ will be used for exploration. The main issue that is to be solved is channel interference [15].

In multiple simultaneous transmissions, the capacity of a wireless network is limited due to interference which is a major problem. In WMNs this problem is removed by mesh routers which have multiple radios. In multi-radios, nodes can send data on multiple channels at the same time and also send and receive data simultaneously. However, the interference is not eliminated due to a specific number of channels. In a wireless mesh network, two nodes can only send and receive data if these nodes are within the transmission range and working on the same frequency channel. In a wireless mesh network at a distance of transmission range, every mesh router has carrier sensing range. Within receiving range, mesh router can generate interference if they are transmitting information and working on the identical frequency channel. When interference arises, it degrades WMN performance, or it can cause transmission losses. In a wireless mesh network, two different types of interference occur. The first one is coordinated and the second one is non-coordinated interference. The non-coordinated interference is categorized as information asymmetry (IA), nearhidden $(\mathrm{NH})$ and far-hidden (FH). If source nodes of multiple links are within receiving a range of each other, then these links are coordinated (CO) interfering links. In this research information asymmetry and near-hidden interference will be minimised and their effect will be compared [20].

\section{Information Asymmetry}

In the event of information asymmetry (IA) interference, both links L1 (A, B) and L2 (C, D) are operating on the same frequency channel. In IA both source nodes $\mathrm{A}$ and $\mathrm{C}$ are outside each other carrier sensing ranges (Cs). Similarly, A and $\mathrm{D}$ are also outside each other carrier-sensing range, but $\mathrm{C}$ and $\mathrm{B}$ are inside each other carrier-sensing ranges. Let $\mathrm{d}$ represents the physical distance between nodes. For IA interference the following terms need to be fulfilled.

$$
\begin{aligned}
& d(A, C)>C s \\
& d(B, C)<C s \\
& d(A, D)>C s
\end{aligned}
$$

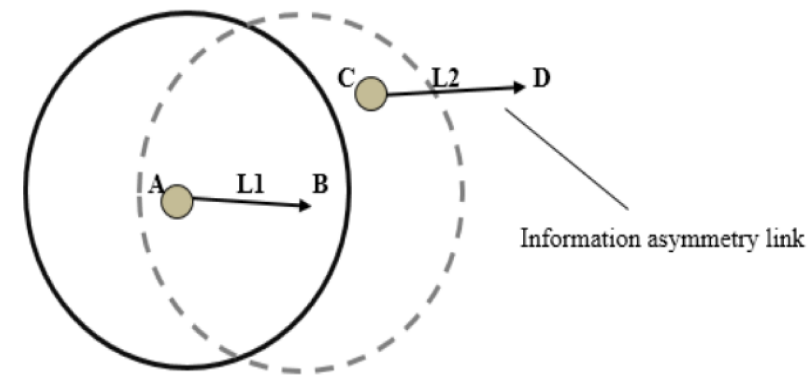

- Carrier sensing range of source

Fig. 2. Information asymmetry interference in wireless mesh network.

In Fig. 2 both source nodes $\mathrm{A}$ and $\mathrm{C}$ are far away from each other carrier sensing ranges (Cs). Similarly, A and D are also far away from each other receiving range, but source $\mathrm{C}$ and receiver $\mathrm{B}$ are inside each other carrier-sensing ranges. In these conditions if $\mathrm{C}$ starts data transmission to $\mathrm{D}$ then $\mathrm{B}$ will sense all the data sent by $C$. In this case $B$ will sense data from both $\mathrm{A}$ and $\mathrm{C}$ and data collision is experienced. The flow on 
L1 (A, B) can be minimised due to interference from L2(C, D).

\section{Near-Hidden Terminal}

In the event of near hidden $(\mathrm{NH})$ interference, the source nodes of both links are far away from each other carrier sensing range. However, the receivers of both links are inside each other carrier sensing range. When both links L1 (A, B) and L2 (C, D) are working on the same frequency channel. Then for near-hidden $(\mathrm{NH})$ interference, the following terms need to be fulfilled:

$$
\begin{aligned}
& d(A, C)>C s \\
& d(B, C)<C s \\
& d(A, D)<C s
\end{aligned}
$$

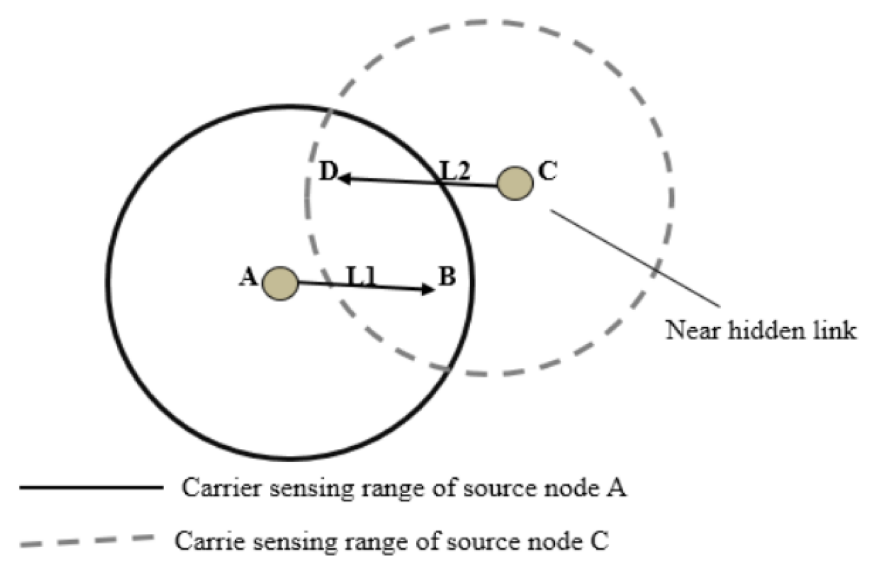

Fig. 3. Near-hidden terminals in a wireless mesh network.

In Fig. 3 source nodes $\mathrm{A}$ and $\mathrm{C}$ are outside each other carrier-sensing range Cs. However, the receivers of both the links are inside the sensing range of each others carrier sensing range. In these links interference occur when node A sends data to $\mathrm{B}$. In the middle of this transmission, node $\mathrm{C}$ also has data to send to node $\mathrm{D}$ at the same frequency channel. The nodes $\mathrm{A}$ and $\mathrm{D}$ are hidden from each other concerning the destination node. Hidden nodes can reduce the capacity of the network because of the possibility of interference. Minimization of IA and NH interference, an optimal channel will be proposed because channel assignment is a major area for dealing channel interference.

\section{E. Channel Assignment in Wireless Mesh Network}

There are different problems confronted by an MRMCWMNs, i.e. channel assignment, node deployment and link scheduling. In MRMC -WMN channels assigning to a radio interface to minimise the interference and attain efficient channel utilisation is done by channel assignment (CA). Channel assignments are used to perform an appropriate mapping among channels and the radios at specific nodes. To minimise interference between WMN links channel assignment are used. The purpose of CA scheme in MRMC-WMN is to improve the combined network capacity and reduced interference and to keep the network connectivity. Channel assignment in MRMWMN will allot channels to the free radio interfaces which are free to get best uses of the channel and for minimisation of interference. The CA schemes are commonly categorised as Fixed (static)and dynamic channel assignment. For CA the technology used will be IEEE $802.11 \mathrm{~b}$. The frequency range of $802.11 \mathrm{~b}$ is $2.4 \mathrm{GHz}, 11$ frequency channels are used in IEEE $802.11 \mathrm{~b}$ frequency band. Non-overlapping channel or orthogonal are those channels which are separated by at least $25 \mathrm{MHz}$ non-overlapping channel do not interfere, in IEEE $802.11 \mathrm{~b}$ only three channels $(1,6,11)$ are currently used that do not overlap with each other. By allotting these non-overlapping channels through the optimum way, it minimises the channel interference. Channel assignment scheme is categorised as static (fixed), dynamic and hybrid channel assignment. In static (fixed) channel assignments different channels can be assigned to a specific node permanently or for a long time with the help of static assignment algorithm [7].

\section{LiterATURE REVIEW}

The basic idea familiarised by the authors to transmit data in a bottleneck collision domain in the overall geographic area is discussed in [9]. The authors displayed that in WMN the capacity of every node is reduced as $\mathrm{O}(1 / \mathrm{n})$. Where $\mathrm{n}$ denote the entire mesh nodes in the wireless mesh network. The authors equate existing proposed function, and they delivered the exact higher boundary on the capacity of any node.

An algorithm of load-aware in a wireless mesh network is suggested in [17], which assigns channels dynamically to multi-radio WMN. The author suggestion needs that after channel assignment that expected traffic loads and paths traversed are take place. The essential, unique feature in his suggestion is that to allot channels entirely based on awareness of interference in the wireless mesh network.

The available network capacity could be increased by using multiple channels. However, it required new protocols fulfil the capacity [11]. The author further discussed that by using multiple interfaces the capacity of multi-channel wireless mesh network could be increased. The author considered the scenario in which multiple interfaces are presented. However, the numbers of the available interfaces are more than the available channels. He offers different interface assignment strategies and proposes new strategies without the adaptations to 802.11, and for those strategies, he also recognises the routing heuristics. The author discussed that in wireless mesh network the frequent channel switching arises many problems. Just like performance degradation and end-to-end delay performance. In this research paper, the capacity of multi-channel WMN is enhanced with the help of multiple interfaces.

Author in [13] supposed that for practical purposes in IEEE 802.11a the overlapping among adjacent channels is so small which can be ignored. In this research, the authors displayed that by using $802.11 \mathrm{~b}$ and calculating the throughput, three channels are separated, i.e. the free distance between two non-overlapping neighbouring channels, and a $10 \mathrm{~m}$ distance is sufficient for two links to send and receive actual amount of data without interference with each other. However, only calculating the network throughput is not enough but also the interference is decreased to come to the results. The supposition of the author is entirely incorrect for 802.11a. It is answered merely that more susceptible spreading technique and higher modulation scheme in 802.11a. 
In WMN every node consists of more than one radio interfaces, and more than one channel can be assigned to that radio for communication [19]. To assign channel through proper manner minimise the overall network interference. On any node number of channel is more than the numbers of radios. The constraint must follow by channel assignment that different channel assigned to the links on any node. This process is called NP-hard problem. For channel assignment distributed and centralised algorithm are designed. Through this algorithm, he developed a semidefinite program formulation of the optimisation problem to achieve edge boundaries on overall network interference.

Author in [7] studied the different constraints of CA in WMN and show the main issues in channel assignment schemes for multipath connectivity, traffic patterns and interference situation. Three different channel assignment schemes are used, i.e. fixed, dynamic and hybrid channel assignment schemed were examined. The main objective of CA algorithm to reduced interference and improve the overall network capacity and to manage the hole network connectivity in WMN. They presented a new MESTIC scheme to associates the mesh connectivity issues and mesh traffic issues to decline interference in a multi-radio mesh network.

In MR-MC WMN multiple channels are assigned to radio interfaces for communication. The objective of the authors is to minimise the network interference through allocating channels to communication links in a network [2]. The number of available channels is more than the number of radios on every node and constraint must be followed by channel assignment. When the number or radios channel is more than the radio links then the interference occurs on that node, and this problem is called NP-hard, and for this problem, the author developed distributed and centralised algorithms for channel assignment. To measure the output achievement by these algorithms, the author developed liner program and semidefinite program formulation to achieve the edge boundaries on network interference.

Author in [6] discussed that in wireless mesh network there are two main types of interference. First one is coordinated $(\mathrm{CO})$ and the second one is non-coordinated (n-CO) interfering links. He further divides the non-coordinated (n-CO) interference links into three types. First one is information asymmetry (IA) the second one is near hidden ( $\mathrm{NH}$ ), and the third one is far hidden (FH) interference (Garettoet al., 2008). The author further discussed these interference links on an MRMC -WMN, and find out all the probabilities of packet loss in these links. Then compare the coordinated (CO) and non-coordinated (n-CO) interference links, and prove that noncoordinated links have high transmission loss as compared to coordinated interference. After that he proposed an analytical model that minimizes this interference.

It was shown in [14] that the non-interfering links such as radio frequency band, traffic pattern and physical modulation (PHY), as well as a multi or single radio system. By using more than one non-overlapping radio frequency channels to improve the capacity of WMNs, and several devices can transmit data on a different channel within a collision domain, and adjacent channel interference (ACI) problem is discussed.

Author in [16] stated the suggestion of dynamic channel- assignment algorithm LYCAS. He delivered an optimisation model to minimising the non-coordinated interference and maximising the network capacity. The authors discussed coordinated and non-coordinated interference and displayed that non-coordinated interference is more destructive than coordinated interference. The author used non-overlapping channel assignment approach to minimise non-coordinated interference. In this paper, decision variable is used for nonoverlapping channel assignment. His objective is to minimise interference and maximise network capacity.

Author in [18] proposed optimisation model that concentrates on the maximisation of network capacity and minimisation of non-coordinated interference operating the effectiveness of non-overlapping channel assignment in MRMC WMNs by offering an optimised channel assignment approach. Through simulation, both spare and dense channel assignment are compared in MRMC-WMN topologies. Non-overlapping channels which are three $(1,6,11)$ of $802.11 \mathrm{~b}$ were considered for channel assignment strategy. In last with the help of OPNET simulator both dense and sparse topologies were concluded. Through simulation, the author shows that proposed model gives $19 \%$ better results as compared to the dense network.

Author in [21] suggested that in this scenario nonoverlapping channels are less than the wireless mesh nodes, so these non-overlapping channels repeatedly assigned to nodes and shared between these nodes. Due to this failure, the channel interference occurs and also degrades the performance of the network. The author has presented a mathematical Linear Programming (LP) model to minimise the interference through a group based channel assignment method. This model determines the channel assignment strategy for the removing of interference. For solving the optimisation function, the Discrete Particle Swarm Optimization (DPSO) are used.

The authors [22] considered a memoryless high power amplifier PAPR-efficiency model, and the auxiliary channel model under low complexity symbol-bysymbol receiver is also derived. Moreover, the achievable spectral efficiency (ASE) which can be viewed as the low bound for any modulation and coding schemes is taken as a figure of merit throughout this paper. By jointly optimizing the time-frequency spacing and clipping ratio to maximization the ASE under the given shaping pulse and modulation format, we show that the ASE of clipping-based MFTN substantially outperforms conventional Nyquist signaling schemes.

\section{PROPOSED INM MODEL}

In this proposed model decision variable, objective function single channel per link constraint, coordinated interference constraint, near-hidden and information asymmetry interference constraints are explained which are given in details. The proposed model that is information asymmetry and near hidden minimisation (INM) Model consist of Near-Hidden and information asymmetry interference constraint. The objectives of this proposed model to improve the channel assignment mechanism. INM model minimise interference and improve the overall capacity of a network.

\section{A. Decision Variable}

In this proposed model the decision variable allots an IEEE 802.11 b channel cj to a link ei. In this optimisation model, the 
following decision will be used. This model state that if on any channel cj the directed link ei is active then it is equal to 1 otherwise 0 . Such type of decision variable is represented as a binary variable [18].

$$
x\left(e_{i} . c_{j}\right)=\left\{\begin{array}{cc}
1 \text { directed link } e_{i} \text { operates channel } c_{j} \\
0 & \text { otherwise }
\end{array}\right.
$$

\section{B. Objective Function}

The objective is to maximise the MRMC-WMN capacity through this proposed model. To achieve the objectives, all the constraints must be considered. Equation (2) shows the objective of the proposed model. For the purpose of the objective function, all the objective are used, and all the constraints must be measured. All the link flows fulfilled over all the links and channels are added.

$$
\max \sum_{Q_{i} \in E} \sum_{c_{i} \in M} x\left(e_{i}, c_{j}\right) \cdot \lambda\left(e_{i}\right) \cdot f\left(e_{i}\right)
$$

\section{Constraints}

Constraints are the limitations of an optimization model, and they display the unwanted results. Below is the set of constraints consist of this proposed channel assignment model.

1) Single Channel per Link Constraint: In this model, the constraint will make sure that each link in the set $\mathrm{Q}$ must be allotted a single channel. This constraint states that if is, a link and $\mathrm{cj}$ is a channel assign to a link then the summation of all channels evaluates to 1 .

$$
\sum_{c_{j} \in M} x\left(e_{i}, c_{j}\right)=1 \quad \forall e_{i} \epsilon Q, c_{j} \in M
$$

2) Coordinated Interference Constraint: In this constraint, if more than one coordinated links operating on the identical frequency channel it does not form intense interference and network performance is not affected or minimised. Capacity is shared among all the interfering links. The following constraints will display in this optimisation model that on which method the capacity is distributed when more than on coordinated links are working on same channel (Shah et al., 2013).

$$
\begin{array}{r}
x\left(e_{i}, c_{j}\right) \cdot \lambda\left(e_{i}\right) \cdot f\left(e_{i}\right)+\sum e_{k} \epsilon c o\left(e_{i}\right) \cdot x\left(e_{k}, c_{j}\right) . \\
\lambda\left(e_{k}\right) \cdot f\left(e_{k}\right) \leq C c_{j} \quad \forall e_{i} \epsilon Q, \quad c_{j} \epsilon M
\end{array}
$$

Fig. 4 consist of coordinated links. The solid line circle shows the transmission range and the upper dotted line circle display the carrier sensing range. There are three links represented in a figure. The source node $\mathrm{A}, \mathrm{C}$ and $\mathrm{E}$ are inside the carrier sensing range of each other. Moreover, these three links share the capacity of a same frequency channel $\mathrm{Cj}$.

3) Near hidden interference constraint: The second constraint in the optimisation model is near hidden. NH links do not work on a fully overlapping channel. Equation (5) shows that if there are more than one near hidden interfering links, then only one channel cj will be assigned to them. Two

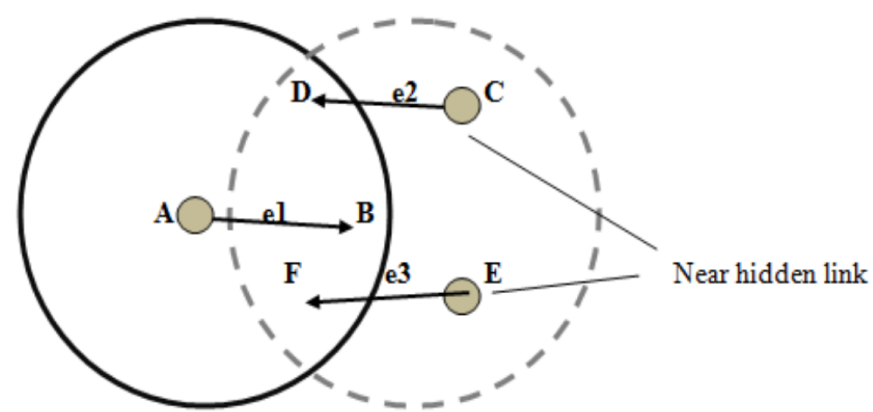

Fig. 4. Coordinated interfering links.

different links ei and ek working on the same channel cj. Then in interfering range, only one of them will be active.

$$
x\left(e_{i}, c_{j}\right) \max \sum_{Q_{i} \in E} \sum_{c_{i} \in M} x\left(e_{i}, c_{j}\right) \cdot \lambda\left(e_{i}\right) \cdot f\left(e_{i}\right)
$$

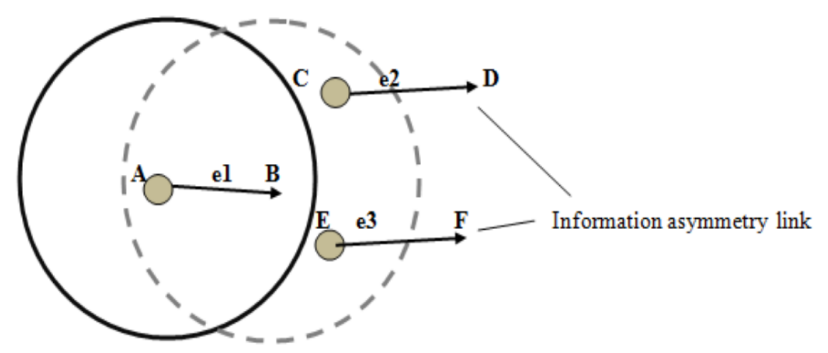

- Carrier sensing range of source node $A$

- - - Carrie sensing range of node B

Fig. 5. Near hidden links.

Fig. 5 explains that $\mathrm{e} 2$ and $\mathrm{e} 3$ are $\mathrm{NH}$ links. The receiver node $\mathrm{D}$ and $\mathrm{F}$ are inside the carrier sensing of source $\mathrm{A}$ which cause near hidden interference. The objective of the model is to minimize this interference by assigning certain channel ei which cannot assign to e2 and e3.

4) Information asymmetry interference Constraint: Equation (6) shows that if there is more than one information asymmetry (IA) interfering links, then only one channel will be assigned to them. Information asymmetry links do not operate on a fully overlapping or common channel. Two different links ei and ek are operational on the identical channel cj. Then in interfering range, only one of them will be active.

$$
\begin{array}{r}
x\left(e_{i}, c_{j}\right)+\sum e_{k} \epsilon I A\left(e_{i}\right) x\left(e_{k} c_{j}\right) \leq 1 \\
\forall e_{i} \epsilon Q, \quad \forall c_{j} \epsilon M, e k \epsilon Q
\end{array}
$$

Fig. 6 shows that e 2 and e 3 are Information asymmetry (IA) links. The links e 2 and e 3 are far away from the receiving range of source node of e1. However, in the range of destination node $\mathrm{B}$ of link el and information asymmetry interference may occur.

5) Near hidden and Information asymmetry interference constraint: This equation shows that if there are multiple near hidden, information asymmetry (NHIA) interfering links 


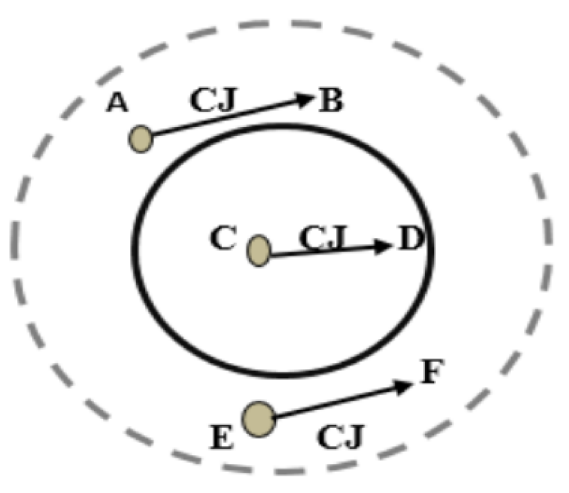

\section{Transmission range}

\section{- - - Carrie sensing range}

Fig. 6. Information asymmetry links.

then they are combined into one set NHIA. Only one channel will be assigned to them which means that $\mathrm{NH}$ and IA links do not work on a fully overlapping or same channel. In these constraints, two different links ek belongs to the set of interfering link of ei and they will not operate on the identical channel. Then in interfering range only a single link are active on channel cj.

$$
\begin{array}{r}
x\left(e_{i}, c_{j}\right)+\sum e_{k} \epsilon N H I A\left(e_{i}\right) x\left(e_{k} c_{j}\right) \leq 1 \\
\forall e_{i} \epsilon Q, \quad \forall c_{j} \epsilon M, e k \epsilon Q
\end{array}
$$

\section{RESUlt AND Discussion}

In this chapter, a detailed discussion is made on the results taken from this research study. This chapter consists of three main sections. In first part different MRMC, wireless mesh topologies were constructed with the help of Matrix Laboratory (MATLAB). Then "A Mathematical programming language", (AMPL) is used for getting near-optimal channel assignment strategy. In the third section, OPNET simulations are used for result verification and analysis.

\section{A. Simulation Parameters}

Before simulations, some research parameters have been considered that are present in Table I. The radio technology that is used in this research is $802.11 \mathrm{~b}$ where frequency channels are 11. The total number of topologies which are used in this research is 4 , and every topology contains 30 mesh nodes. Every node contains three numbers of radios. The transmission capacity of a link is $11 \mathrm{mbps}$. Each node has a transmission range which is 10 meters. The carrier sensing range of each node is $2.6^{*} 10$ meters. The flow demand is changed from 50 to 500 Packets/sec. Poisson traffic generator is used for traffic generation, and that is flow. For all network topologies, the total simulation time is 3 simulation minutes.

\section{B. MATLAB Topology Construction}

In MATLAB 4 different topologies of MRMC are generated. Each topology consists of 30 nodes. In these four topologies, the interference effect of IA and $\mathrm{NH}$ is to be
TABLE I. PARAMETERS USED DURING Simulation RESUlts

\begin{tabular}{|l|l|}
\hline Parameter & Value \\
\hline Radio Technology & IEEES02.11b \\
\hline Numbers of Topology & 4 \\
\hline Number of Nodes & 30 \\
\hline Radios Per Node & 3 \\
\hline Transmission Capacity & $11 \mathrm{Mbps}$ \\
\hline Transmission Range & 10 meters \\
\hline Carrier Sensing Range & $2.6^{*} 10$ meters \\
\hline Simulation Time & 3 minutes \\
\hline Terrain area & $80 \mathrm{~m} \times 80 \mathrm{~m}$ \\
\hline
\end{tabular}

checked. Every node has a transmission range and carrier sensing range which are 10 meters and 26 meters, respectively. In transmission, range node can send and receive information successfully. While in sensing range nodes can only sense the other nodes. Interference may be generated when more than one node tries to communicate on the same channel within carrier-sensing range of each other.

In coordinate system 80 by 80 -meter area is taken and construct four different topologies. Then find out information asymmetry (IA) and near-hidden (NH) links in these topologies.

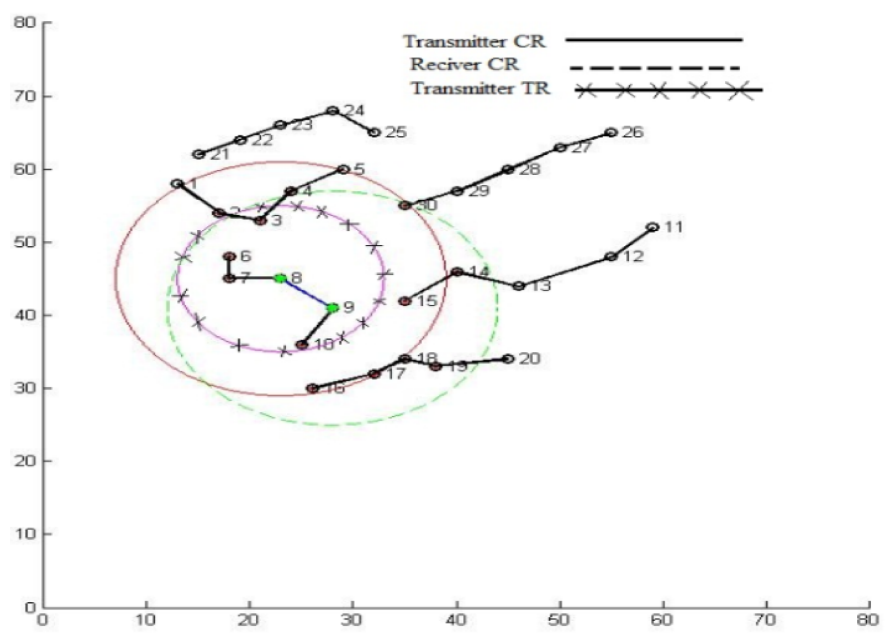

Fig. 7. MRMC-WMN MATLAB generated topology 1.

Fig. 7, 8, 9 and 10 consist of WMN topologies which are constructed in MATLAB. In these four figures, the $\mathrm{x}$ and $\mathrm{y}-$ coordinates are $80 \times 80$ meters. These four figures consist of three types of circles cross line, solid line and dotted line circle. Which represent the transmission range of source node, carrier sensing range of source node, and carrier sensing range of receiver node, respectively.

Fig. 7 consist of WMN topology which is created in MATLAB. In Fig. $7(8,9)$ link have the following coordinated links i.e. $(2,3),(3,4),(4,5),(6,7),(7,8),(9,10),(16,17)$, $(17,18)$. While a set of information asymmetry (IA) links is $(19,20)$ and set of near hidden $(\mathrm{NH})$ links is $(14,15)$. Those links which are present in the carrier sensing range of a source node is said to be coordinated links. Those links which are far away from the sensing range of source node but present in the receiver sensing range is said to be information asymmetry links, i.e. $(19,20)$. Near hidden are those links in which source nodes are far away from the sensing range, but its receiver is present in the carrier sensing range, i.e. $(14,15)$. 


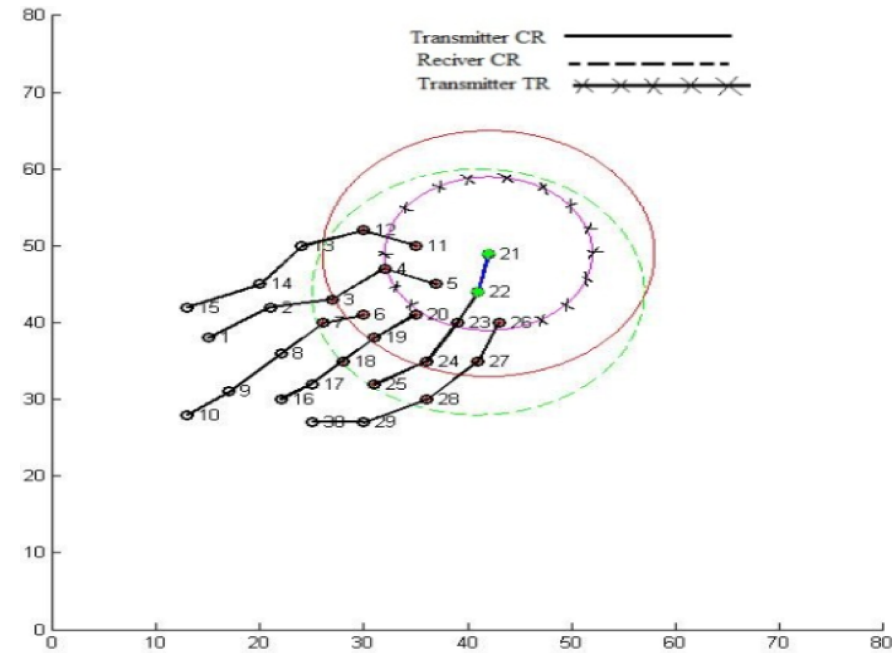

Fig. 8. MRMC-WMN MATLAB generated topology 2.

In Fig. $8(21,22)$ link have the following coordinated links. i.e. $(4,5),(6,7),(11,12),(12,13),(19,20),(22,23),(23,24)$, $(24,25),(26,27),(27,28)$ while set of IA links is $(7,8),(28$, $29)$ and the set of NH consist of $(3,4),(18,19)$. Similarly in Fig. $9(6,7)$ links have the following coordinated links. i.e. (2, $3),(3,4),(4,5),(7,8),(8,9),(11,12),(12,13),(13,14),(22$, $23),(23,24),(24,25),(26,27),(27,28),(28,29)$ while the set of information asymmetry (IA) links are $(9,10),(29,30)$ and the set of near hidden links are $(1,2),(19,20),(21,22)$.

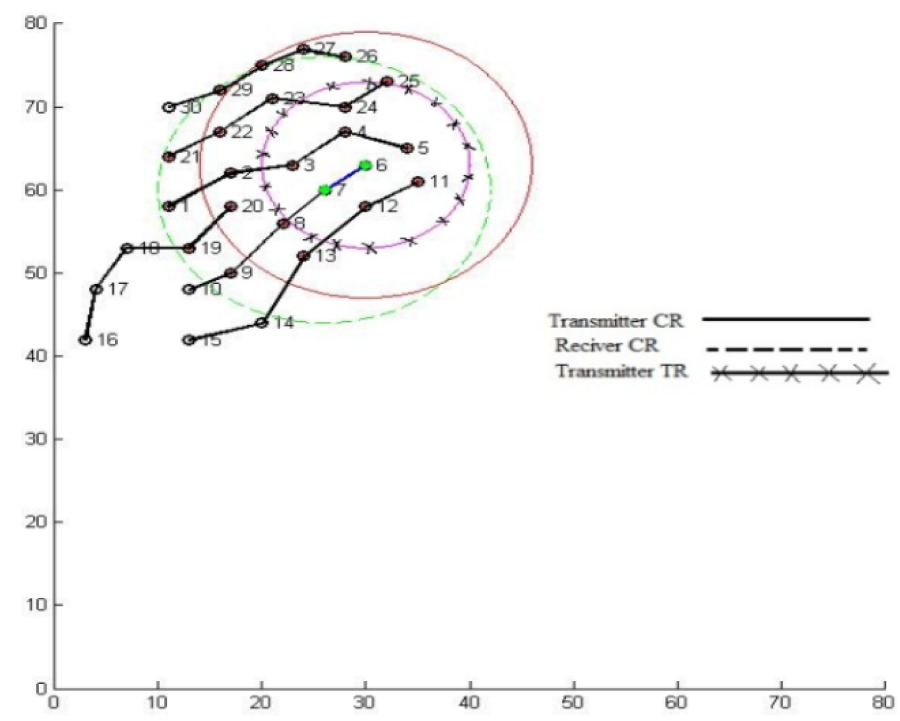

Fig. 9. MRMC-WMN MATLAB generated topology 3.

In Fig. $10(11,12)$ links have the following coordinated links i.e. $(12,13),(13,14),(19,20),(26,27),(27,28)$. While set of information asymmetry (IA) links are $(14,15),(28,29)$ and the set of near hidden $(\mathrm{NH})$ links is $(18,19)$.

The Table II consists of coordinated links, information asymmetry and near hidden links. In this table, the first column consists of considered links. The second column shows information asymmetry (IA) links and the third column consist of near hidden (NH). From Fig. 9 these IA and NH links are

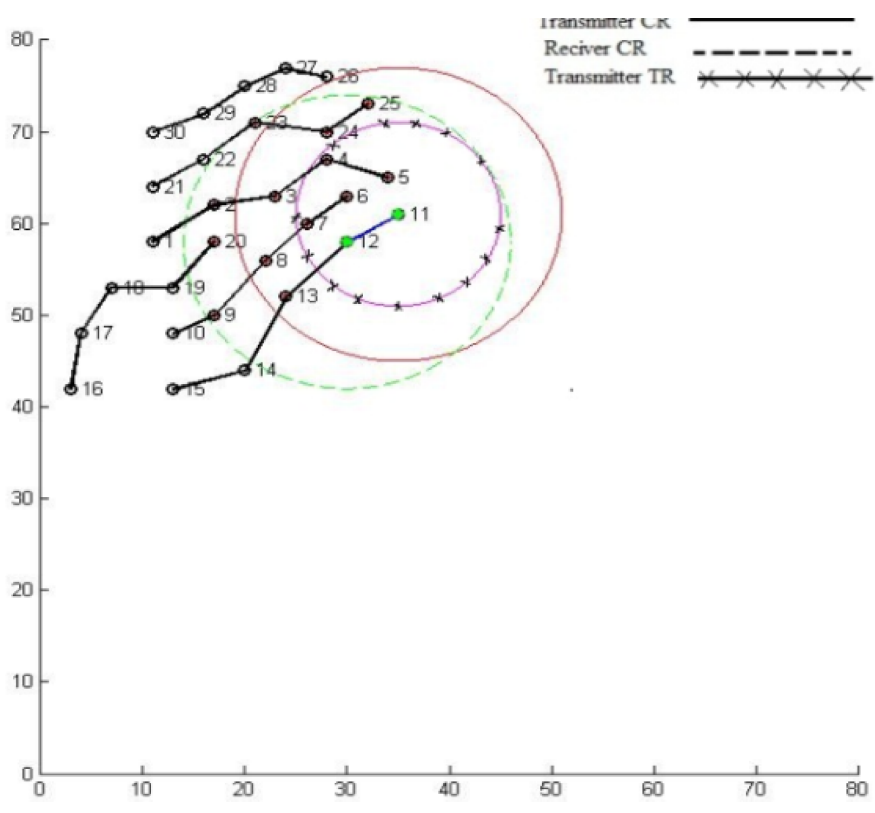

Fig. 10. MRMC-WMN MATLAB generated topology 4 .

taken. For example consider link $(1,2)$ have the following information asymmetry links, i.e. $(4,5),(24,25)$. And near hidden $(\mathrm{NH})$ links consists of $(6,7),(12,13),(28,29)$. Due to the effect, IA and NH interfering links the flow of $(1,2)$ link will be reduced.

Table II consist of 30 nodes in which IA and NH nodes links of a consider link are shown.

\section{AMPL Results}

The result obtained from MATLAB should be given to a mathematical programming language (AMPL) solver, and that gives us channel assignment information. In MATLAB software four different topologies are generated through which all the coordinated, information asymmetry and near hidden links have been finding out. The obtaining results given to AMPL which perform the linear programming (LP) proposed a model. To assign channels to different network nodes is performed by AMPL gurobi solver. The channel allocation is near optimal, and the flow demand is changed from 50-500 packets per seconds on every link.

Fig. 11 is one of the topologies that has been taken. This topology consists of 30 nodes. The above figure consists of snapshots. During execution of AMPL software, these snapshots are taken. The binary variables are used, 0 is used for no channel, and one is used for the presence of channels. Same traffic load is assigned to every link through AMPL, and the flow demand is changed from 50-500 packets per second. Due to channel sharing, some channels carry more data traffic than other channels. In the proposed model, the objective functions are used to achieve an aggregate capacity of all links. In IEEE $802.11 \mathrm{~b}$ for channel assignment, three non-overlapping channels $(1,6$, and 11) are used. For a solution, the gurobi solver is preferred. For solving linear programming models, the gurobi solver is used. For the actual implementation of the proposed model, the "mm.txt" file is used. For output of the proposed model the "solve" command issued. The "display" 
TABLE II. SET OF NEAR HiddEN AND INFORMATION ASYMMETRY LINKS OF 30 NODES WMN TOPOLOGY

\begin{tabular}{|l|l|l|}
\hline Links & Information Asymmetry Links (IA) & Near Hidden Links \\
\hline$(1,2)$ & $(4,5)(24,25)$ & $(6,7)(12,13)(28,29)$ \\
\hline$(2,3)$ & NIL & $(11,12)(27,28)$ \\
\hline$(3,4)$ & NIL & NIL \\
\hline$(4,5)$ & NIL & NIL \\
\hline$(6,7)$ & $(9,10)(29,30)$ & $(1,2)(19,20)(21,22)$ \\
\hline$(7,8)$ & $(14,15)$ & $(18,19)$ \\
\hline$(8,9)$ & NIL & $(17,18)$ \\
\hline$(9,10)$ & NIL & $(16,17)$ \\
\hline$(11,12)$ & $(9,10)$ & $(2,3)(23,24)$ \\
\hline$(12,13)$ & NIL & $(1,2)(18,19)$ \\
\hline$(13,14)$ & NIL & $(18,19)$ \\
\hline$(14,15)$ & NIL & $(17,18)$ \\
\hline$(16,17)$ & $(1,2)$ & $(9,10)$ \\
\hline$(17,18)$ & $(2,3)(21,22)$ & $(8,9)(14,15)$ \\
\hline$(18,19)$ & $(3,4)(22,23)$ & $(7,8)(13,14)$ \\
\hline$(19,20)$ & $(4,5)(23,24)$ & $(6,7)(12,13)$ \\
\hline$(21,22)$ & $(4,5)(24,25)$ & $(6,7)(27,28)$ \\
\hline$(22,23)$ & $(12,13)$ & NIL \\
\hline$(23,24)$ & NIL & $(11,12)$ \\
\hline$(24,25)$ & NIL & NIL \\
\hline$(26,27)$ & NIL & NIL \\
\hline$(27,28)$ & NIL & $(2,3)(21,22)$ \\
\hline$(28,29)$ & $(7,8)$ & $(1,2)$ \\
\hline$(29,30)$ & NIL & NIL \\
\hline
\end{tabular}

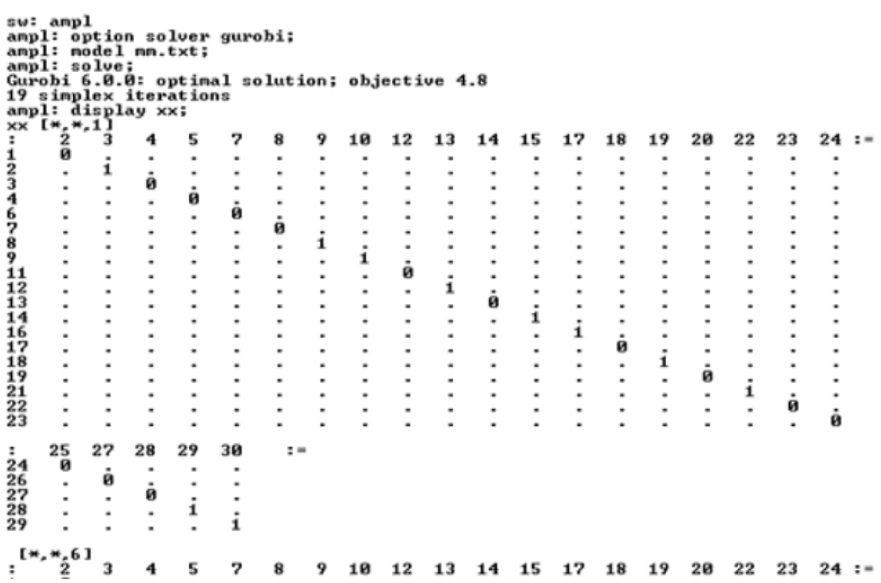

Fig. 11. 11AMPL channel assignment results.

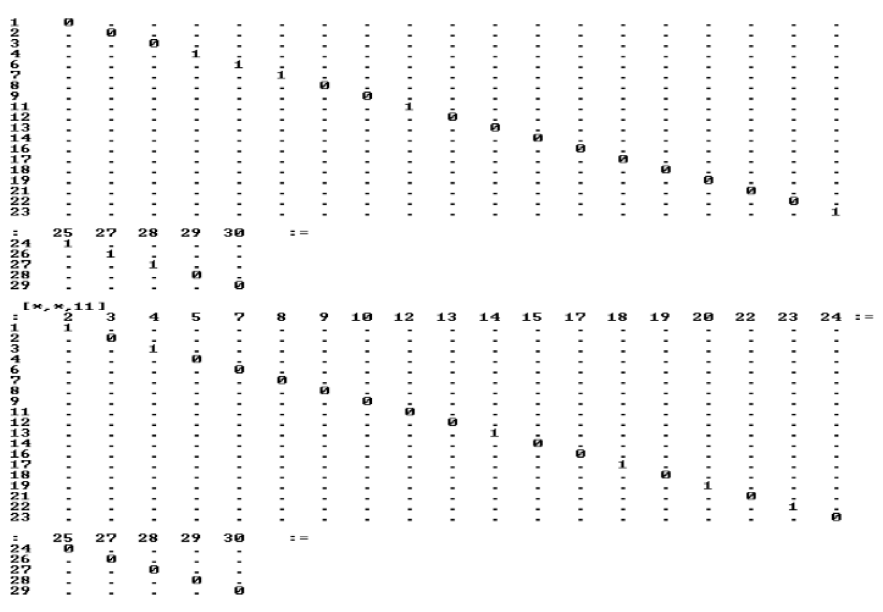

Fig. 12. 11AMPL channel assignment results.

command is used to show the channel assignment results which are 1 or 0 .
TABLE III. Proposed Model Channels Assignment

\begin{tabular}{|l|l|}
\hline Node & Channel Assigned \\
\hline$(1,2)$ & 11 \\
\hline$(2,3)$ & 1 \\
\hline$(3,4)$ & 11 \\
\hline$(4,5)$ & 6 \\
\hline$(5,6)$ & 6 \\
\hline$(6,7)$ & 6 \\
\hline$(7,8)$ & 1 \\
\hline$(8,9)$ & 1 \\
\hline$(9,10)$ & 6 \\
\hline$(10,11)$ & 1 \\
\hline$(11,12)$ & 11 \\
\hline$(12,13)$ & 1 \\
\hline$(13,14)$ & 1 \\
\hline$(14,15)$ & 6 \\
\hline$(15,16)$ & 1 \\
\hline$(16,17)$ & 11 \\
\hline$(17,18)$ & 1 \\
\hline$(19,20)$ & 11 \\
\hline$(20,21)$ & 1 \\
\hline$(21,22)$ & 11 \\
\hline$(22,23)$ & 1 \\
\hline$(23,24)$ & 11 \\
\hline$(24,25)$ & 6 \\
\hline$(25,26)$ & 6 \\
\hline$(26,27)$ & 6 \\
\hline$(27,28)$ & 6 \\
\hline$(28,29)$ & 1 \\
\hline$(29,30)$ & 1 \\
\hline & \\
\hline
\end{tabular}

The gurobi solver is selected for a solution. This solver is used for linear programming models. The implementation of the proposed model is stored in " $m m$.txt" file. Solve command gives output or objective of the proposed model. The channel assignment results that are 0 or lis assigned by "display" command. Binary variables that show links or channel binding is represented by "xx". For example $\mathrm{xx}[*, *, *]$ shows $\mathrm{xx}$ [sender link, receiving link, channel assigned]. For xx [2, 3, 11] show channel 11 is assigned to a link $(2,3)$.

Table III is made on the bases of Fig. 11. The table consists of node value and the assigned channel value. The table consists of two columns, the first column shows the number of nodes and the second column represent a number of the assigned channel to each link, and these are non-overlapping channels, i.e. (1, 6, and 11). These channels are assigned randomly to the nodes through optimal channel assignment strategy.

\section{Simulation in OPNET}

In this thesis, all the scenario are designed and created by OPNET modeller. Many choices are given by OPNET modeller, i.e. selecting area and placement of nodes in that area. For example, in OPNET modeller a scenario is built which consist of 30 nodes and area selected is $80 * 80$ meter as indicated in Fig. 12. In this research, four different scenarios are discussed and their information asymmetry (IA) and near hidden $(\mathrm{NH})$ results are compared.

In Fig. 12 shows simulation scenario for 30 nodes. In which every node is linked to its adjacent node and these nodes have no mobility and does not change its positions. Each node has its particular properties. For example, channel assigning to a radio nodes, power level, and packet size and internet protocol (IP) address. In this topology, coordinates are identical to MATLAB topology. 


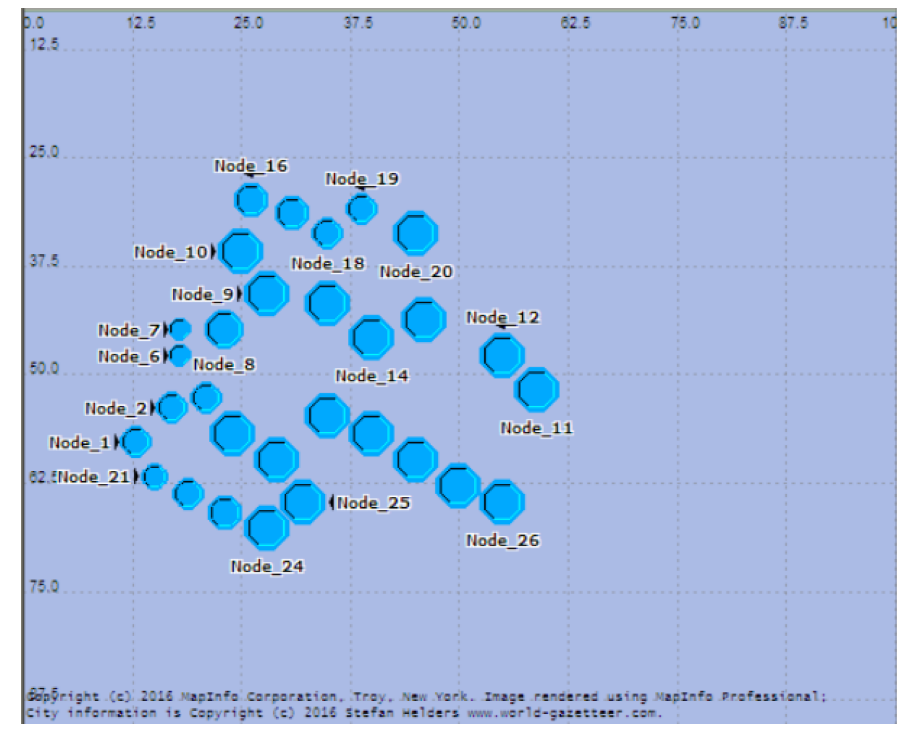

Fig. 13. OPNET 30 node topology of proposed (INM) models.

TABLE IV. SimUlation RESUlts OF IA

\begin{tabular}{|l|l|l|l|l|l|l|}
\hline $\begin{array}{l}\text { Flow de- } \\
\text { mand }\end{array}$ & $\begin{array}{l}\text { Total } \\
\text { capacity } \\
\text { Of a } \\
\text { network }\end{array}$ & $\begin{array}{l}\text { Network } \\
\text { Capac- } \\
\text { ity(30N) }\end{array}$ & $\begin{array}{l}\text { Network } \\
\text { Capac- } \\
\text { ity(30N) }\end{array}$ & $\begin{array}{l}\text { Network } \\
\text { Capac- } \\
\text { ity(30N) }\end{array}$ & $\begin{array}{l}\text { Network } \\
\text { Capac- } \\
\text { ity(30N) }\end{array}$ & $\begin{array}{l}\text { Average } \\
\text { network } \\
\text { capacity }\end{array}$ \\
\hline Packet/sec & Packet/sec & Packet/sec & Packet/sec & Packet/sec & Packet/sec & Packet/sec \\
\hline 50 & 1250 & 1133 & 1008 & 1145 & 1168 & 1113.5 \\
\hline 100 & 2500 & 2161 & 1970 & 2136 & 2183 & 2132.5 \\
\hline 150 & 3750 & 2980 & 2503 & 2616 & 2726 & 27068.25 \\
\hline 200 & 5000 & 3302 & 2587 & 2664 & 2962 & 2878.75 \\
\hline 250 & 6250 & 3530 & 2588 & 2667 & 3146 & 2982 \\
\hline 300 & 7500 & 3653 & 2589 & 2668 & 3261 & 3042.75 \\
\hline 350 & 8750 & 3848 & 2590 & 2669 & 3306 & 3103 \\
\hline 400 & 10000 & 3953 & 2592 & 2670 & 3338 & 3138.25 \\
\hline 450 & 11250 & 4121 & 2595 & 2673 & 3339 & 3182 \\
\hline 500 & 12500 & 4240 & 2598 & 2675 & 3347 & 3215 \\
\hline
\end{tabular}

\section{E. Simulations Results in OPNET}

Table IV displays the information asymmetry (IA) summary results for each topology. The data in each column consists the results of IA. The Table IV consists of seven columns. The first columns consist of flow demand that varies from 50 to $500 \mathrm{packet} / \mathrm{sec}$ for every topology. The second column consists of total network capacity. The third, fourth, fifth and six columns show the results of four different topologies. Each topology consists of 30 nodes. The last column shows the average IA results for all the four topologies.

Table V displays the near-hidden $(\mathrm{NH})$ summary results for each topology. The data in each column consist the results of NH. The table 4.5 consists of seven columns. The first columns consist of flow demand that varies from 50 to 500 packet/sec for every topology. The second consist of the total capacity of a network. The third, fourth, fifth and six columns show the results of four different topologies. Each topology consists of 30 nodes. The last column shows the average NH results for all the four topologies.

Fig. 13 presents the comparison of 30 nodes for information asymmetry (IA) and near hidden (NH) topology. The grey line graph represents the network capacity of near hidden $(\mathrm{NH})$. Blackline graph represents the network capacity of information asymmetry (IA). In Fig. 13 the horizontal line values
TABLE V. Simulation Results of NH

\begin{tabular}{|l|l|l|l|l|l|l|}
\hline $\begin{array}{l}\text { Flow de- } \\
\text { mand }\end{array}$ & $\begin{array}{l}\text { Total } \\
\text { capacity } \\
\text { Of a } \\
\text { network }\end{array}$ & $\begin{array}{l}\text { Network } \\
\text { Capac- } \\
\text { ity(30N) }\end{array}$ & $\begin{array}{l}\text { Network } \\
\text { Capac- } \\
\text { ity(30N) }\end{array}$ & $\begin{array}{l}\text { Network } \\
\text { Capac- } \\
\text { ity(30N) }\end{array}$ & $\begin{array}{l}\text { Network } \\
\text { Capac- } \\
\text { ity(30N) }\end{array}$ & $\begin{array}{l}\text { Average } \\
\text { network } \\
\text { capacity }\end{array}$ \\
\hline Packet/sec & Packet/sec & Packet/sec & Packet/sec & Packet/sec & Packet/sec & Packet/sec \\
\hline 50 & 1250 & 1180 & 1036 & 533 & 1124 & 968.25 \\
\hline 100 & 2500 & 2234 & 2129 & 1087 & 2251 & 1925.25 \\
\hline 150 & 3750 & 2916 & 2600 & 1480 & 2779 & 2443.75 \\
\hline 200 & 5000 & 3270 & 2610 & 1673 & 2969 & 2630.5 \\
\hline 250 & 6250 & 3509 & 2613 & 1927 & 3082 & 2782.75 \\
\hline 300 & 7500 & 3605 & 2615 & 2058 & 3150 & 2857 \\
\hline 350 & 8750 & 3758 & 2617 & 2075 & 3240 & 2922.5 \\
\hline 400 & 10000 & 3839 & 2618 & 2131 & 3316 & 2976 \\
\hline 450 & 11250 & 3951 & 2620 & 2144 & 3398 & 3028.25 \\
\hline 500 & 12500 & 4082 & 2621 & 2257 & 3475 & 3108.75 \\
\hline
\end{tabular}

represent the flow demand in packet/sec, which are varying from 50 to 500 packet/sec. Vertical line values shown on the graph represent for both IA and NH topologies. Whenever the number of flow demand changes the network capacity of both $\mathrm{IA}$ and $\mathrm{NH}$ is change.

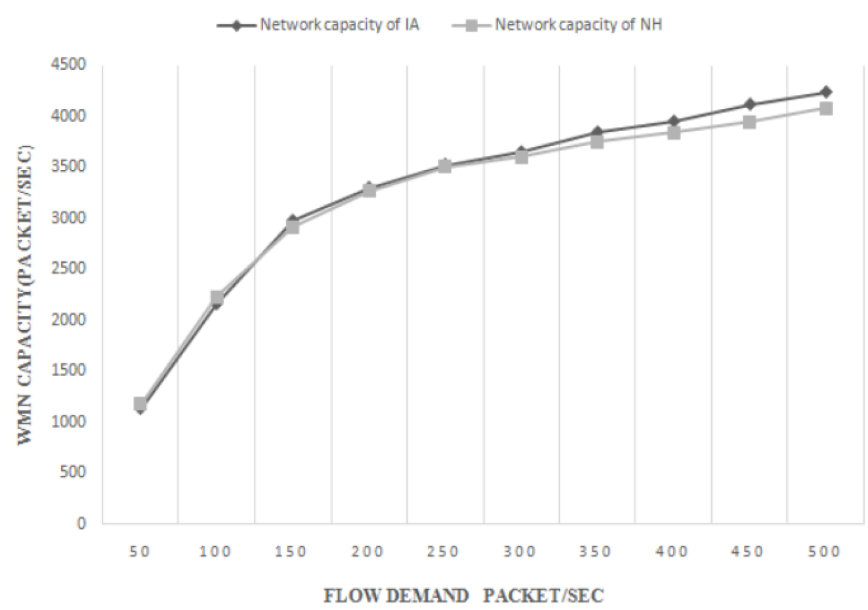

Fig. 14. Capacity comparison of IA and NH in WMN Topology I.

Fig. 14 shows the comparison of 30 nodes for the information asymmetry (IA) and near hidden (NH) topologies. In Fig. 14 all the values are taken from table 4 and 5. The grey line represents the near-hidden $(\mathrm{NH})$ network capacity graph, and the black line represents the information asymmetry (IA) network capacity graph. The $\mathrm{x}$-axis represents the flow demand in packet/sec. The y-axis represents wireless mesh network capacity for both IA and NH topologies. The behaviour of a graph shows that the flow demand change the network capacity of both IA and NH are also changed.

Fig. 15 shows the compression of Information asymmetry (IA) and near hidden (NH) topologies. These results have been taken from wireless mesh topology which consists of 30 nodes. For Fig. 15 the entire values have been selected from Tables $\mathrm{IV}$ and $\mathrm{V}$. The lower grey line indicates the result of $\mathrm{NH}$ and the upper black line indicate the result of IA. On the x-axis, the value represents the flow demand, and on the y-axis, the values represent the network capacity of IA and $\mathrm{NH}$. The graph shows that the flow demand changed the network capacity also changed for both IA and NH topologies.

Fig. 16 shows the comparison of information asymmetry (IA) and near hidden (NH) topologies. The topology consists 


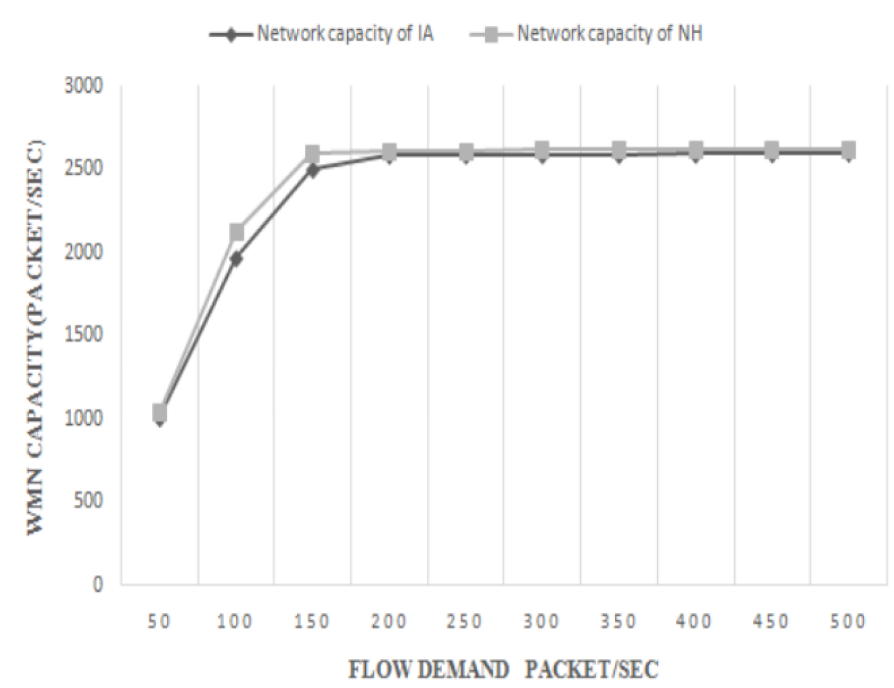

Fig. 15. Capacity comparison of IA and NH in WMN Topology 2.

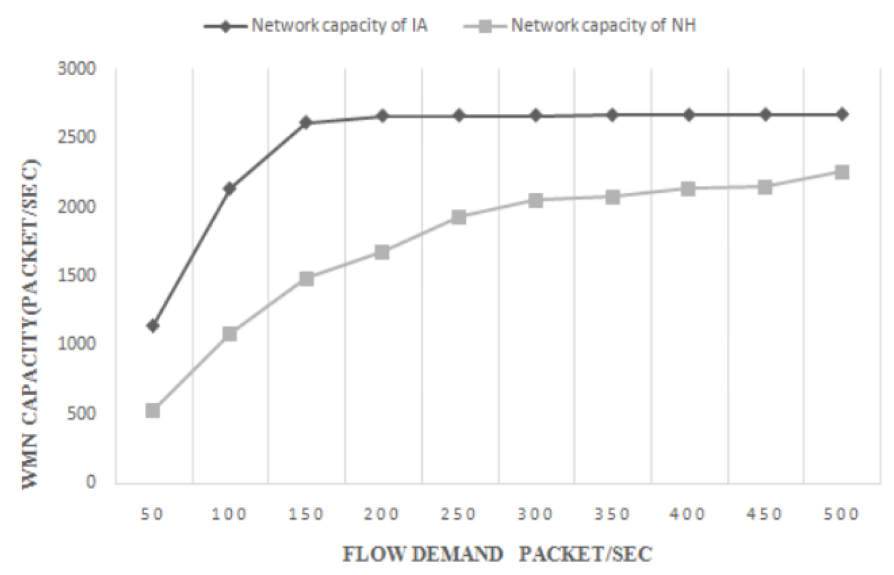

Fig. 16. Capacity comparison of IA and NH in WMN Topology 3.

of 30 nodes. In Fig. 16 the graph consists two lines. The black line represents the IA network capacity, and the grey line indicates the $\mathrm{NH}$ network capacity. On x-axis, the values represent the flow demand. Moreover, the flow demand varies from 50 to $500 \mathrm{packet} / \mathrm{sec}$. On y-axis, the value shows the network capacity. The behaviour of graph represents that the flow demand varies the network capacity of IA and $\mathrm{NH}$ also change.

Fig. 17 is an average capacity comparison of information asymmetry (IA) and near hidden (NH) topologies. This figure graphically indicates $\mathrm{NH}$ and information asymmetry topologies by two line graphs the grey and black line. The grey line indicates the average network capacity of $\mathrm{NH}$ and the black line indicates the average capacity of IA. In Fig. $17 \mathrm{x}$-axis values represent the average flow demand for four different topologies. The flow demand value varies from 50 to 500 packet/sec, while the $\mathrm{y}$-axis values represent the average network capacity for both IA and NH topologies. Fig. 17 shows that $\mathrm{NH}$ interference is more concerning IA interference.

Table VI displays average results for both information asymmetry (IA) and near hidden (NH) topology. Table VI consists of seven columns. The first columns consist of flow

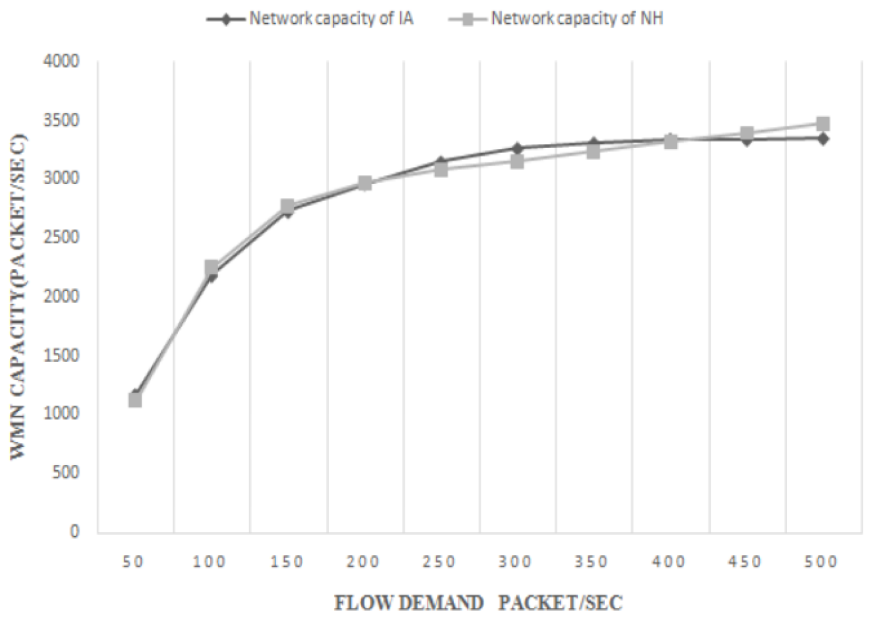

Fig. 17. Capacity comparison of IA and NH in WMN Topology 4.

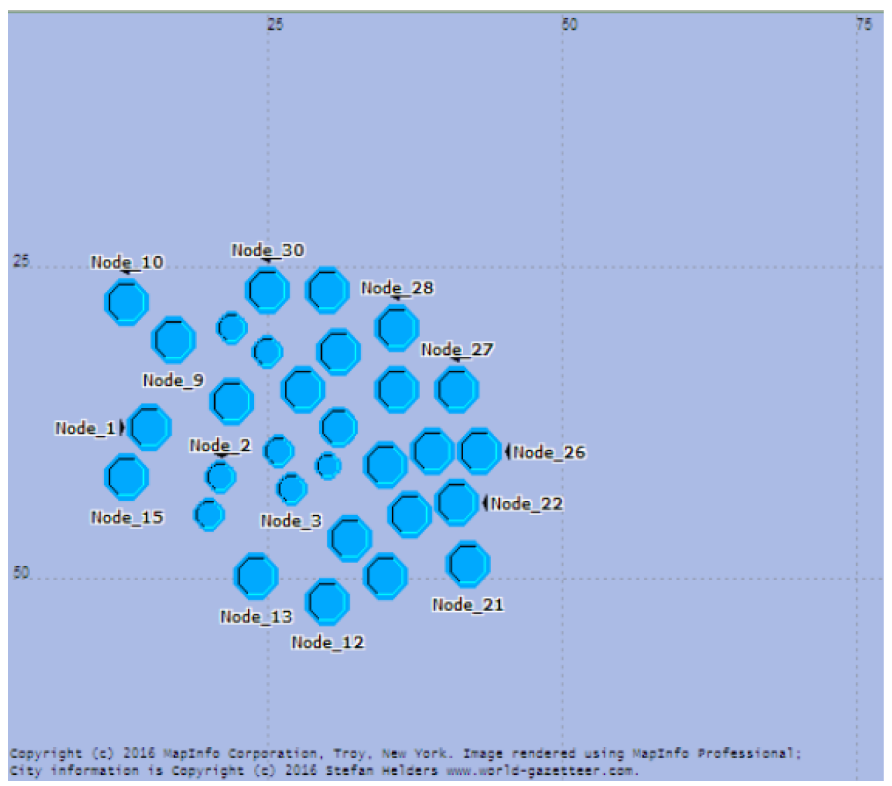

Fig. 18. Average capacity comparison of IA and NH.

demand that varies from 50 to 500 packet/sec for every topology. The second column shows the network flow demand. The third column shows the fulfil network capacity of IA and the fourth one consist of a percentage of IA. The fifth column shows the $\mathrm{NH}$ fulfil network capacity and the percentage of $\mathrm{NH}$ is shown in six columns, and the seven columns consist of the difference of IA and NH results.

\section{F. INM (Proposed) Model Results}

In this section results are taken from the proposed model (INM) are presented. The results are compared with the existing model (OCAM). For comparison, a new WMN topology is constructed in OPNET that is given in Fig. 18.

Fig. 19 shows a capacity comparison of INM (information asymmetry, near-hidden minimization) proposed model topology and OCAM (optimized channel Assignment) existing model. This figure graphically indicates INM and OCAM topologies by two line graphs the grey and black line. The grey 
TABLE VI. AVERAGE RESUlt OF IA AND NH

\begin{tabular}{|l|l|l|l|l|l|l|}
\hline Packet/sec & $\begin{array}{l}\text { Network } \\
\text { Flow } \\
\text { demand }\end{array}$ & $\begin{array}{l}\text { IA fulfill } \\
\text { network } \\
\text { capacity }\end{array}$ & $\begin{array}{l}\text { Percentage } \\
\text { of IA }\end{array}$ & $\begin{array}{l}\text { NH } \\
\text { fulfill } \\
\text { network } \\
\text { capacity }\end{array}$ & $\begin{array}{l}\text { Percentage } \\
\text { of NH }\end{array}$ & $\begin{array}{l}\text { Difference } \\
\text { between } \\
\text { IA and } \\
\text { NH }\end{array}$ \\
\hline 50 & 1250 & 1113.5 & $89.08 \%$ & 968.25 & $77.46 \%$ & $11.62 \%$ \\
\hline 100 & 2500 & 2112.5 & $84.5 \%$ & 1925.25 & $77.01 \%$ & $7.49 \%$ \\
\hline 150 & 3750 & 2706.25 & $72.16 \%$ & 2443.75 & $65.16 \%$ & $7 \%$ \\
\hline 200 & 5000 & 2878.75 & $57.57 \%$ & 2630.5 & $52.61 \%$ & $4.96 \%$ \\
\hline 250 & 6250 & 2982 & $47.71 \%$ & 2782.75 & $44.52 \%$ & $3.19 \%$ \\
\hline 300 & 7500 & 3042.75 & $40.57 \%$ & 2857 & $38.09 \%$ & $2.48 \%$ \\
\hline 350 & 8750 & 3103 & $35.46 \%$ & 2922.5 & $33.4 \%$ & $2.06 \%$ \\
\hline 400 & 10000 & 3138.25 & $31.38 \%$ & 2976 & $29.76 \%$ & $1.62 \%$ \\
\hline 450 & 11250 & 3182 & $28.28 \%$ & 3028.25 & $26.91 \%$ & $1.37 \%$ \\
\hline 500 & 12500 & 3215 & $25.72 \%$ & 3108.75 & $24.87 \%$ & $0.85 \%$ \\
\hline
\end{tabular}

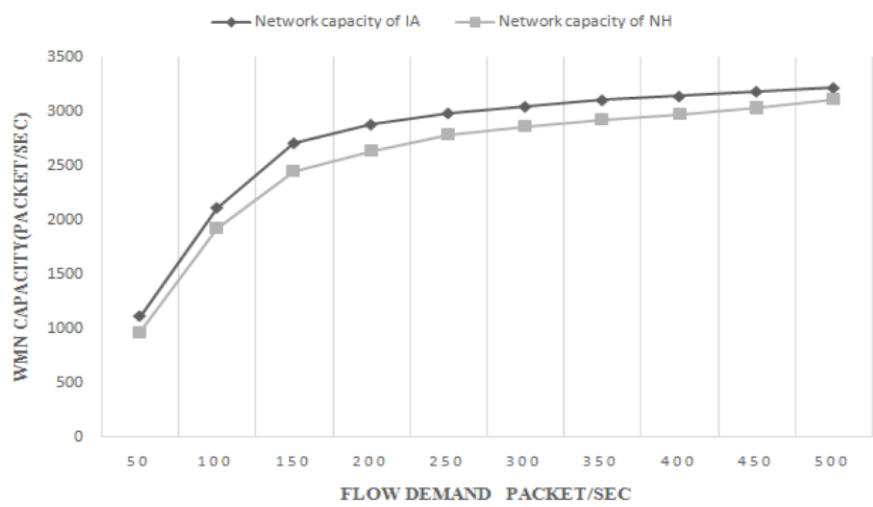

Fig. 19. OPNET 30 node topology for comparison of INM and OCAM.

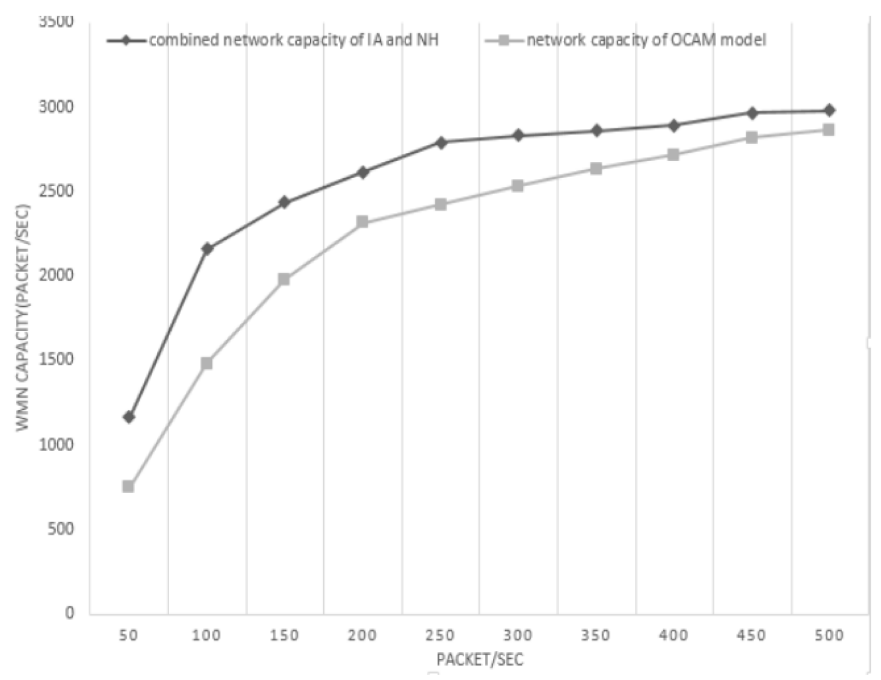

Fig. 20. Comparison of INM and OCAM model of 30 nodes WMN.

line indicates the network capacity of OCAM (existing model) and the black line indicates the capacity of INM (proposed model). X-axis values represent the flow demand. The flow demand value varies from 50 to 500 packet/second. While the $y$-axis values represent the network capacity for both NHIA and OCAM topologies.

Table VII shows the achieved capacity of both INM and OCAM model. The results are given in percentage format to shows the difference in results. The average is taken from all the flow demands that show that INM performs $7 \%$ better that OCAM model. The results are also given in Fig. 19 which
TABLE VII. RESULTS OF INM AND OCAM MODEL FOR WMN TOPOLOGY 1

\begin{tabular}{|l|l|l|l|l|l|l|}
\hline Packet/sec & $\begin{array}{l}\text { Total } \\
\text { capacity } \\
\text { Of a } \\
\text { network }\end{array}$ & $\begin{array}{l}\text { Network } \\
\text { Capac- } \\
\text { ity of } \\
\text { INM } \\
\text { Pro- } \\
\text { posed } \\
\text { model }\end{array}$ & $\begin{array}{l}\text { Network } \\
\text { Capac- } \\
\text { ity of } \\
\text { OCAM } \\
\text { (Ex- } \\
\text { isting) } \\
\text { model }\end{array}$ & $\begin{array}{l}\text { Percentage } \\
\text { Capac- } \\
\text { ity of } \\
\text { INM } \\
\text { pro- } \\
\text { posed } \\
\text { model }\end{array}$ & $\begin{array}{l}\text { Percentag£ } \\
\text { Capac- } \\
\text { ity of } \\
\text { OCAM } \\
\text { (Ex- } \\
\text { isting) } \\
\text { model }\end{array}$ & $\begin{array}{l}\text { Percentag } \\
\text { im- } \\
\text { prove- } \\
\text { ment } \\
\text { of INM } \\
\text { over } \\
\text { OCAM }\end{array}$ \\
\hline 50 & 1250 & 1165 & 752 & $93.2 \%$ & $75.2 \%$ & $18 \%$ \\
\hline 100 & 2500 & 2159 & 1486 & $86.36 \%$ & $74.3 \%$ & $12.06 \%$ \\
\hline 150 & 3750 & 2438 & 1982 & $65.01 \%$ & $51.41 \%$ & $13.6 \%$ \\
\hline 200 & 5000 & 2616 & 2315 & $52.32 \%$ & $46.3 \%$ & $6.02 \%$ \\
\hline 250 & 6250 & 2789 & 2423 & $44.62 \%$ & $38.76 \%$ & $5.86 \%$ \\
\hline 300 & 7500 & 2831 & 2535 & $37.74 \%$ & $33.8 \%$ & $3.94 \%$ \\
\hline 350 & 8750 & 2860 & 2636 & $32.68 \%$ & $30.12 \%$ & $2.56 \%$ \\
\hline 400 & 10000 & 2893 & 2715 & $28.93 \%$ & $27.15 \%$ & $1.78 \%$ \\
\hline 450 & 11250 & 2964 & 2818 & $26.34 \%$ & $25.04 \%$ & $1.3 \%$ \\
\hline 500 & 12500 & 2980 & 2865 & $23.84 \%$ & $22.27 \%$ & $1.55 \%$ \\
\hline
\end{tabular}

shows that after 350 packets per second which is a high data rate the results are consistent. It shows that the proposed model is more consistent in case of high data rate demand.

\section{CONCLUSion}

This research has been successfully done to compare the interference effect of information asymmetry (IA) and near hidden $(\mathrm{NH})$ wireless mesh network over OCAM (existing) model. Then the combined interference effect of IA and $\mathrm{NH}$ has been presented on the INM (proposed) model. Moreover, then compare the INM (proposed) model and OCAM (existing) model.

The OPNET results show that the near-hidden and information asymmetry (INM) gives better performance than OCAM model. Both of the models consist of 30 nodes. Where the Near Hidden $(\mathrm{NH})$ and information asymmetry (IA) interference is high between the nodes, the proposed optimisation model gives improved results regarding an increase in network capacity. The results are given in percentage format to shows the difference in results. The average is taken from all the flow demands that show that INM performs 7\% better that OCAM model. The results are also given in Fig. 20 which shows that after 350 packets per second which is a high data rate the results are consistent. It shows that the proposed model is more consistent in case of high data rate demand.

\section{A. Future Work}

In future work the research work can be expanded to large wireless mesh networks, i.e. the number of wireless mesh nodes may increase to hundreds. The performance can be checked over $802.11 \mathrm{~g}$ and $802.11 \mathrm{n}$ radios technologies instead of $802.11 \mathrm{~b}$. In this research far-hidden terminals are not considered so in the future far-hidden interference can also be considered.

\section{REFERENCES}

[1] Ajayi, A, O., A, A, Adigun., And I, W, Oladimeji. (2015). A Review of Routing Protocols for Practical Rural Wireless Mesh Networks (WMNs).International Journal of ComputerApplications, 114(16).

[2] Angelakis, V., S, Papadakis.,V,Siris., and A,Traganitis.(2008). Adjacent channel interference in 802.11a: Modeling and testbed validation. In Proc. of IEEE Radio and Wireless Symposium.IEEE, no. 2, 591594. 
[3] Bansal, D., S,Sofat., and A,K,Gankotiya. (2010). Selfish MAC Misbehavior Detection in Wireless Mesh Network.International conference on advances in Computer engineering.IEEE computer society,doi:10.1109/ACE.2010.91. 130-133

[4] Bukkapatanam,V., A,A,Franklin., and C,S,R,Murthy.(2009).Using PartIAlly Overlapped Channels for End-to-End Flow Allocation and Channel Assignment in Wireless Mesh Networks, in Proc. of IEEE ICC, 2009.10.1109/ICC.2009.5199559.1 - 6 .

[5] Fu,y.(2013). Research of Wireless MESH Network Performance based on NSTUns. Computational and Information Sciences (ICCIS), 2013 Fifth International Conference on 1EEE.10.1109/ICCIS.2013.354. 1339 -1342 .

[6] Garetto,M., T,Salonidis., and E,W,Knightly. (2008). Modeling per-flow through-put and capturing starvation in CSMA multi-hop wireless networks, IEEE/ACM Transactions on Networking (TON), 16(4): 864-877.

[7] Huang,Y., X,Yang., S,Yang., W,Yu., and X,Fu.(2011). A Cross-Layer Approach Handling Link Asymmetry for Wireless Mesh Access Networks. IEEE transactions on vehicular technology, 60(3):10451058.

[8] Iqbal,F., M,Y,Javed., and A,Naveed.(2014).Interference-aware multipath routing in wireless mesh network. EURASIP Journal on Wireless Communications and Networking, doi:10.1186/1687-1499-2014-140

[9] Jun, j., and M, L,Sichitiu. (2003).The nominal capacity of wireless mesh networks, IEEE Wireless Communications 10 (5) pp. 8, 2003.

[10] Kaur, N., and J, S,Saini. (2013). Performance ENHancement of 802.11 based Wireless Mesh Network by usingMulti- Radio Multi-Channel. International Conference on Green Computing, Communication and Conservation of Energy -(ICGCE), 10.1109/ICGCE.2013.6823402.7176.

[11] Kyasanur, P., N, H,Vaidya.(2005). Routing and interface assignment in multi-channel multi-interface wireless networks. Wireless Communications and Networking Conference, IEEE .4: 20512056.

[12] Mahmud,S,A., S,Khan., S,Khan., and H,Al-Raweshidy.(2006). A Comparison of MANETs and WMNs: CommercIAl Feasibility of Community Wireless Networks and MANETs. In Proceedings of the First International Conference on Access Networks (AcessNets'06),10.1145/1189355.1189373. 18-24.

[13] Mishra,A., V,Shrivastava., S, Banerjee., and W,Arbaugh. (2006). partIAllyoverlappedchannels not considered harmful .In ACM Sig Metrics, 6:6374.

[14] Nachtigall,J., A,Zubow., and J,P,Redlich.(2008).the impact of adjacent channel interference in multi-radio systems using ieee 802.11.in Proc. IWCMC '08, Crete Island, Greece, Aug. 2008.10.1109/IWCMC .151 874-881.

[15] Naz, K., (2016). Minimization of near hidden interferance in multi radio multi-channel wireless mesh network. (Unpublished doctoral dissertation). The University of Agriculture, KPK, Pakistan.

[16] Naveed,A., S,S,KaNHere.(2008).Channel Assignment in Multi-Radio Multi-Channel Wireless Mesh Networks, School of Computer Science and Engineering, University of South Wales, October 2008.

[17] Raniwala, A., K,Gopalan., and T,Chiueh.(2010).Centralized Channel Assignment and Routing Algorithms for Multi-Channel Wireless Mesh Networks. In Mobile Computing and Communications Review, 8: 5065.

[18] Shah, S., H, Hussain. and M,Shoaib.(2013). Minimizing noncoordinated interference in multi-radio multi-channel Wireless Mesh Networks (MRMC -WMNs),24-28.

[19] Sombrutzki,R.,A,Zubow., M,Kurth., and J,P,Redlich. (2006). Selforganization in community mesh networks the berlin roofnet in OperatorAssisted (Wireless Mesh) Community Networks, 1st Workshop on, sept.10.1109/WOACN.2006.337188 . 1 -11.

[20] Subramanian, A,P., H, Gupta., S,R,Das., and J,Cao.(2008). Minimum Interference Channel Assignment in Multi radio Wireless Mesh Networks. IEEE transactions on mobile computing, 7(12):1459-1473.

[21] Manikandan, A., and Y,Palanichamy.(2015).Optimized Group Channel Assignment Using Computational Geometry over Wireless Mesh Networks.Hindawi Publishing Corporation,Mobile Information Systems, Volume 2015, Article ID 718079, 18 pages.

[22] Peng, S., Liu, A., Song, L., Memon, I., Wang, H. (2018). Spectral Efficiency Maximization for Deliberate Clipping-Based Multicarrier FasterThan-Nyquist Signaling. IEEE Access, 6, 13617-13623. 